been designed had no difficulty in controlling the wheelchair, once he had been given the instructions.

\title{
EMPLOYMENT FROM A WHEELCHAIR
}

\author{
By Charles Dunham \\ General Secretary, British Limbless Ex-Service Men's Association
}

You may wonder why I as a fairly mobile amputee should have accepted an invitation to speak about employment from a wheelchair-the explanation is that my Association is especially interested in all forms of employment and rehabilitation of the physcially handicapped and we have some experience of the problems of wheel-chair users, expecially double leg amputees and others with severe leg wounds.

As I see it, this question of employment can be divided into two issues-the one is employment or living within the patient's home and the other outside employment in normal industrial conditions. Whichever section is considered, there is overall an immediate requirement for the wheelchair to be suited to the needs of the user. It is essential that the chair should be comfortable, light and easy to handle, either by the patient or his assistant. The wheelchair for the severely disabled is not just a means of getting about, it is an extension of his body and one which is put on test all day, every day. Others will be speaking on the necessity for individual assessment of the types of work for which particular categories of disabled are best suited and of the principles in designing wheelchairs. I merely emphasise the relationship between the user and his chair and the fact that, in our view, the approach to assessment of working ability is the extent of the ability left to the individual and how best this might be developed rather than the degree of his disablement.

More and more we find in today's modern, scientific and technical age that man need no longer rely upon his physical strength alone to live or to work effectively. All over the country, and indeed in many areas of the world, we find persons with severe physical disablement and chronic disease working effectively and doing jobs which but a few years ago would have been considered impossible for them. One reason for this has been the development of modern engineering and other techniques, more and more of the energy needed to operate machines, for example, is provided by the machine itself, and the physical demands on the operator are that much less. One would wish that this new approach to industrial techniques and organisation and methods could be more widely applied and the good examples of the few tirms followed more closely. Unfortunately one often finds that employers tend to give preference in employment to those with comparatively minor disabilities because they, often quite erroneously, think there is no easy solution for the employment of the wheelchair user. The architectural barriers, the difficulties which the wheelchair user faces in everyday life in public and other buildings are immense. Sedentary occupations which would otherwise be eminently suitable are often quite impossible because the works or offices are built up a pile of steps, with no ramps. difficult doorways and frequently no lifts. When these obstacles are overcome there are the difficulties of doing the job itself. This calls for under- 
standing both on the part of the employer and of the trade union concerned; fit the job to the worker, bring it within his reach-a study of works organisation could result very often in substantial breakdown of the process involved making it not only suitable for the severely disabled but also less fatiguing for general able-bodied workers. Some undertakings have already done this and their works are the happier and more productive for it. Industry in general could benefit substantially from similar re-appraisal of the effort involved in work. Modifications of machinery and equipment can make some processes ideally suitable for wheelchair users; where the operative had previously to stand it may be possible with adaptions that he could sit in his chair, provided the whole operation at slightly below elbow level can be brought within his reach. Doorways between particular shops and other access might need to be widened. On the clerical side the wheelchair user often finds that the desk provided is unsuitable; he cannot get close enough to it to work, and the records or files he needs are set away from him, often at groundfloor level. Careful selection of the desk and adjustable or detachable wheelchair armrests can get him close to his work, and good sense in office administration should provide for his immediate records to be readily accessible, within easy reach, without moving from his desk.

Provided the severely disabled wheelchair user is given best possible aids, with goodwill and understanding he is just as capable of earning his living and contributing to the national economy as his able-bodied counterpart.

The Disabled Persons (Employment) Act contains the general authority for employment of the disabled and requires employers of 20 or more workers to employ a quota of registered disabled, at present 3 per cent. This Act undoubtedly brought about a social revolution and a new approach. Our experience, however, is that the Act, of itself, is very often not the answer to the employment of those with severe disabilities, and almost all that is done is to provide employment opportunity for the severely handicapped appears dependent upon goodwill. There are shortcomings in the State's provisions, but this is not the time or place to deal with them, I mention them only to emphasise that legislation of itself is insufficient, goodwill and understanding must prevail and whilst much has been achieved, more employers and representatives of trades unions have yet to realise the benefits of re-appraisal. There is an old adage amongst those who work in rehabilitation fields and it is that any new technique or method developed to make the person with severe disablement more effective on the job proves equally valuable for the able-bodied, often substantially reducing the strains of work.

Getting to and from his work often presents real problems for the wheelchair user; the severely disabled war pensioner of course is now provided with a mini motor-car at State expense and can carry his collapsible wheelchair with him in his car quite conveniently. The day cannot be far off when this excellent facility will be made available to all who have need of such transport because of their condition; on the basis that it is illogical to keep men and women idle merely because they cannot get to and from their jobs, it is surely better to spend money to help keep the disabled self-supporting rather than on relief through the social services.

It must, however, be accepted that some users of wheelchairs will not be capable of undertaking employment under ordinary conditions, e.g. where regular medical or other treatment is necessary, and such work as they can do must be 
done in their own homes. One of the major objects in rehabilitation is to enable the disabled person to function in his home within the limits of disability. Some fortunately are able to make adjustments appropriate to their needs; others do remarkably well in managing with what they have but with great difficulty and at a tremendous loss of time and energy. There is an urgent need for housing that meets the special needs of those who lost their mobility, and in this respect I welcome the recent publication of guidance to architects through the R.I.B.A. and the steps taken by the Central Council for the Disabled to give publicity to this need, which may result in substantial future improvement. There is a need for employers, and this could perhaps best be achieved by arrangement with the Welfare Services Department of Local Authorities, to consider whether any part of their work could be undertaken by the severely disabled in their own homes, on an out-worker basis. Some useful forms of production can be achieved in this way; the work involved of necessity must be simple, but it is essential that it should form at least some part of the ultimate production; the severely disabled to be encouraged to do work at home must be convinced that what he is doing is part of a productive effort and not merely an object of recreational handicraft or diversional interest; in the main they do not want to be recipients of sympathy or charity. Nothing can be a substitute for the taking home or receiving a wage packet every week; the severely disabled himself is uplifted by the possibility, and the nation's economy is the more solvent for the effort which he is able to make given understanding and the opportunity.

\title{
THE USER'S VIEWPOINT
}

\author{
By O. A. Denly, M.B.E., F.H.A. \\ Chairman, Disabled Drivers' Association
}

Patience. One of the first things a disabled person has to learn when facing the use of a wheelchair for the rest of his life is patience.

Patience to cope with architectural barriers.

Patience in waiting for improvements in the design of wheelchairs.

Patience to learn how to do things indirectly which can no longer be done directly.

Patience in waiting for others to learn that because something has been done a certain way for years it is not necessarily the best way.

Patience to learn how to surmount or ignore psychological barriers.

Patience in waiting to be taught how to make the best use of a wheelchair.

Patience in waiting for the powers that be at the Ministry of Health to learn that the active disabled wheelchair users cannot be brought down to the lowest common denominator of mass production in the issue of wheelchairs.

I am afraid that after nearly twenty years of living in a wheelchair my patience is fast running out, and I have many harsh things to say this morning. I am not unaware of the improvements that have been made-for example immediately after the last war there was not a single suitable folding transit wheelchair available 